\title{
Maternal Reports of Play Dates of Clinic Referred and Community Children
}

\author{
Fred Frankel $\cdot$ Jim Mintz
}

Published online: 13 November 2010

(c) The Author(s) 2010. This article is published with open access at Springerlink.com

\begin{abstract}
Recent interventions have focused upon play dates as a means to improve friendships. However, no measures have been published which quantify play date quality. An important characteristic of play dates in this regard may be the amount of conflict. We present the development of such a measure. We compare maternal reports of play dates for 112 community subjects with 48 subjects referred for peer problems (mean age $=$ 8.7 years). We found that clinic-referred subjects had significantly fewer hosted and invited play dates than the community subjects. The mean conflict on play dates was significantly lower for the community subjects than for the clinic-referred subjects. We obtained significant correlations between conflict on play dates and measures of problem behaviors. Our results support the position that conflict on play dates is an important area to target in social skills training programs. The scale may prove useful to clinicians and researchers by facilitating screening and assessing interventions directed towards improving play dates.
\end{abstract}

Keywords Social skills · Friendship - Play dates · Peer relationships $\cdot$ Peer conflict

F. Frankel ( $\square)$

UCLA Semel Institute, 300 UCLA Medical Plaza,

Suite 1271, Los Angeles, CA 90095, USA

e-mail: ffrankel@mednet.ucla.edu

J. Mintz

University of Texas Health Science Center,

San Antonio, TX, USA

\section{Introduction}

We define the term "play date" as a prearranged play session between only two children at the home of one of the children. It has been an integral part of the social vernacular of parents for at least 20 years (Ladd 1992; Parke and Bhavnagri 1989). Reports of play date prevalence are consistent across studies: Newson and Newson (1976) reported that $72 \%$ of upper middle class mothers reported that their child had friends play in their home "most weeks." Lougee and Kenniston (1975, reported in Gottman 1983) found that about $55 \%$ of boys and $90 \%$ of girls, 6-8 years old reported playing with their friends at home.

Parents who invite peers into their homes have children who have more play dates in both theirs and their peer's homes (Ladd et al. 1988), have children with a larger range of playmates and more consistent play partners (Ladd and Golter 1988), and have children with closer and more stable friendships (Krappman 1986, cited in Ladd and Hart 1992). Thus play dates may serve as a pathway for the formation and maintenance of best friendships (Frankel 2010; Frankel and Myatt 2003).

The benefits of play dates may extend beyond the home (Ladd and Golter 1988). Steinberg (1986) reported that peer pressure had less effect on latchkey children who played at a friend's house when compared to children who describe themselves as "hanging out." We have found that the number hosted play dates by children with Autism Spectrum Disorders (ASD), but not play dates at another child's home, was significantly and positively correlated with the following behavior observed on the schoolyard at recess: joint engagement (mutual and direct social behavior with peers such as offering objects, conversing, toy-taking, and other activities with a turn-taking structure) and 
positive peer response to the initiations of the child with ASD (Frankel et al. 2010a).

Play dates may have a large role to play in a child's overall adjustment. Nangle et al. (2003) looked at popularity measures at school as well as dyadic interactions (i.e. play dates) for factors which mitigate loneliness and depression. Their results suggest that sociometric popularity was important as setting the stage for relationship development, but dyadic friendships, manifested through play dates, have the most impact on feelings of loneliness and depression. Parker and Asher (1993) found that having dyadic friendships, friendship quality, and popularity made unique contributions to the prediction of loneliness.

A measure of play date outcome can contribute to assessment of social adjustment. Children differ from one another in how well liked they are, how many friends they have, as well as the quality of their dyadic relationships (Hartup 1996). Success on one of these dimensions does not predict success on the other, as evidenced by the findings of Gest et al. (2001) that $31 \%$ of well liked children reported not having a mutual friend.

Previous research suggests that mothers can be key informants about their child's play dates. They found that most $(82 \%)$ parent initiators of play dates were mothers (Ladd and Hart 1992). Therefore maternal ratings of play dates may offer a low cost method of assessment of changes in important aspects of play dates.

In attempting to develop a parent report of the outcome of play dates, it is important to select behaviors that parents can readily observe. Quality of friendship can be measured in a number of ways, although perhaps the easiest for parents to observe is how much conflict occurs on play dates, as they may be called upon to help settle these disputes. Failing to resolve conflict puts the friendship at risk (Hartup 1996). Supporting this contention, Gottman (1983) was able to differentiate which non-friend dyads, who had not had previous play dates with each other, would "hit it off" to later become friends. Gottman reported that children who "hit it off" differed in the ease at which they could engage and re-engage in common ground activities without significant conflict. Other authors have indicated that avoidance of conflict is a key factor in determining if a new friendship would continue (Ladd 1992).

Number of friends is also an important outcome variable to consider in a measure of play dates. Children with more friends are happier at school, have fewer adjustment problems (Ladd et al. 1996), are more prosocial, and less likely to tease others (Gest et al. 2001). However, having parents report on the number of friends is fraught with methodological problems, due to difficulties in establishing defining features of "friend" (cf., Gifford-Smith and Brownell 2003).
The frequency of play dates is easily observable for parents, since parents are intimately involved in arraigning play dates for elementary school children. Frequency of play dates may reflect number of friends as well as intensity of friendship. More frequent play dates with the same friend may indicate a stronger friendship, while more play dates with a larger number of friends may indicate success in establishing a larger friendship network. Thus measuring frequency of play dates may provide a valuable index of social success and side step issues inherent in defining friendships.

Related to frequency of play dates, reciprocity of accepted invitations may be another aspect of friendship success readily assessed by parents. Since it is common etiquette not to invite yourself to another's house, noting the locations of play dates, whether they occur in the subject's home or whether the subject is invited to a peer's home, will reflect play date reciprocity. Noting the locations of play dates has been informative for both of our previously published intervention studies (Frankel et al. 2010b; Laugeson et al. 2009). In both studies we have been more successful in increasing the frequency of play dates hosted in the subject's home as compared with those where the subject is the guest at another peer's home. As we noted above, only hosted but not invited play date frequency showed significant correlations with positive peer interactions on the school playground (Frankel et al. 2010a).

Supporting our stated focus on play date measure development, clinical interviews with parents referring their children for treatment for peer problems to our social skills program suggest (a) that children with peer problems may have fewer play dates (sometimes spanning months since the last play date) and that (b) the few play dates that clinic-referred children have are characterized more conflict than the play dates of children who are not referred for social skills treatment.

Social skill intervention programs have begun to focus upon decreasing conflict on play dates as a means to improve peer relationships (Cousins and Weiss 1993; Frankel et al. 1997; Pfiffner and McBurnett 1997; Koegel et al. 2005). Our manualized treatment has devoted 5 of 12 sessions to fostering play dates (Frankel and Myatt 2003). Subsequent studies showed that social gains generalized to home and school (Frankel et al. 1997, 2007, 2010b). Thus, measurement of conflict on play dates would be an important addition to quantify improvements resulting from social skills interventions.

The present study describes the development of a measure of play date quantity and quality based upon maternal ratings. In order to assess discriminative validity, a clinic-referred sample was compared with a community sample. In order to assess concurrent validity, correlations 
between social skills, problematic behaviors and play date conflict for the clinic-referred sample were also assessed.

\section{Method}

\section{Sample Description}

Two groups of subjects were derived from different sources. One group was composed of 48 nonpsychotic children (Clinic group; 35 boys and 13 girls) whose parents enrolled them in our outpatient social skills treatment program. This program was a clinical service offered within the child outpatient clinic of a large university hospital. The prevalent parental complaint was that the children were having difficulty making and/or keeping friends. Other frequent complaints were peer rejection and being teased by peers in school. Referral to the program was made by other professional staff at the hospital (43.8\%), professionals in private practice (14.6\%), personnel at the child's school (4.2\%), or by the child's parents in response to "word of mouth" about the treatment program (16.7\%). In $20.8 \%$ of cases the source of referral was not recorded. Fifteen subjects were prescribed stimulant medication, 11 subjects were prescribed other psychotropic medication (i.e., bupropion, carbamazepine, clomipramine, clonodine, divalproex sodium, fluoxetine, gabapentin, risperidone, sertraline) either alone, in combination with each other or in combination with stimulants, and the remaining 22 subjects were not prescribed medication at the time of assessment.

Diagnoses were assessed by structured interview which included the Diagnostic Interview for Children and Adolescents (Reich 2000) and a measure of attention problems and oppositional behavior (SNAP-4, Atkins and Pelham 1991). Diagnoses for this sample was Attention Deficit/ Hyperactivity Disorder for 34 subjects, Oppositional Defiant Disorder for 18 subjects, Separation Anxiety Disorder for 7 subjects, various other anxiety disorders for 7 subjects, and various other affective disorders for 3 subjects (subjects could meet criteria for more than one diagnosis). Five subjects failed to meet criteria for any diagnosis.

The purpose of the present study was to develop scales that would apply equally to both genders so that we could include girls in our analyses of treatment effects. Peer problems were overrepresented in boys by a ratio of approximately $3: 1$ in the clinic group, which was typical for children being referred for social skills training. If the gender ratio of the Community group were matched to the Clinic group, then there would not be sufficient girls to explore if the resulting factor structure was similar for boys and girls. Therefore, we recruited more girls in the community sample so that girls and boys could be included in factor analysis. Thus, the second group of subjects was composed of 112 children (Community group; 40 boys and 72 girls) whose mothers were approached in public community settings with their child present.

Racial/ethnic distribution was $80.9 \%$ white, $4.8 \%$ African-American, 5.3\% Hispanic, 5.3\% Asian and 3.6\% of other racial/ethnic backgrounds.

Table 1 presents the mean demographic characteristics of the two samples. Parent socio-economic status (SES) was calculated using the procedure described by Hollingshead (Four factor index of social status. Available from PO Box 1965 Yale Station, New Haven, CT 06520, 1975 unpublished). Use of archival clinic data and collection of the community sample data were approved by the UCLA Institutional Review Board.

\section{Measures}

We developed the Quality of Play Questionnaire (QPQ) based upon parent concerns reported during telephone screening interviews of children referred to the treatment program and subsequent mental status interviews with clinic-referred children (cf., Frankel and Myatt 2003) prior to the collection of data for the present study. We also included common play date activities as these might influence the nature of interactions observed on the play date. We began the QPQ by defining a play date as a oneon-one experience. This was because telephone intakes of clinic-referred mothers revealed that some parents would also consider inviting two or more children to play or a birthday party as a play date. We asked parents to rate the last play date they were able to observe that their child had with the peer invited over most often during the past month. Parents were asked for the first name of this playmate in order to focus upon recall of a specific pay date. Items 8-17 asked about the nature of interactions. These items were worded so as not to assign blame to a particular child for a negative interaction and required parents to make judgments of "Not at all", "Just a little", "Pretty much", and "Very much" for this play date. Item 18 asked parents to recall the number of times their child was invited

Table 1 Demographic variables and social skill rating scale scores for clinic and community groups

\begin{tabular}{lcrlll}
\hline Demographic variable & \multicolumn{2}{l}{ Mean } & & & \multicolumn{2}{l}{ Standard deviation } \\
\cline { 2 - 3 } \cline { 5 - 6 } & Community & Clinic & & Community & Clinic \\
\hline Child age & 8.8 & 8.6 & & 1.7 & 1.5 \\
Socio-economic status & 53.8 & 54.1 & & 8.3 & 10.2 \\
Percent single parents & 8.2 & 14.6 & & \\
Percent non-Anglo- & 21.8 & 12.5 & & \\
$\quad$ American & & & & \\
\hline
\end{tabular}


to another child's house as the only invited guest in the last month (Invited play dates) and item 19 asked parents to recall the number of times their child invited another child to their house as the only invited guest (Hosted play dates) in the last month. We include this measure as "Appendix 1".

The Social Skills Rating System (Gresham and Elliott 1990) was a questionnaire consisting of 55 items rated as either "Never," "Sometimes," or "Very often." The instrument has been divided into two major scales: Social Skills (four subscales) and Problem Behaviors (three subscales). We further consider only two of the four Social Skills subscales as being relevant to peer interactions (the other two measured parent-child interaction). The assertion subscale measured making friends and playing well with them (10 items, e.g., "Makes friends easily."); the selfcontrol subscale measured appropriate response to provocation by peers (10 items, e.g., "Responds appropriately to teasing from friends or relatives of his or her own age."). The Problem Behavior scale was composed of three subscales of six items each. The externalizing subscale (e.g., "Argues with others.") measured inappropriate behaviors involving verbal or physical aggression, arguing and poor control of temper; the internalizing behavior subscale (e.g., "Appears lonely.") measured anxiety, sadness, loneliness and low self-esteem; the hyperactivity subscale (e.g., "Is easily distracted.") measured excessive movement and impulsive reactions. Parents were also asked to rate the importance of each item, but importance ratings were not scored. The manual (Gresham and Elliott 1990) reported test-retest reliabilities of .87 and .65 for Social Skills and Problem Behaviors Scales, respectively. The authors also reported that correlations of parent version with teacher $(\mathrm{r}=.36)$ and peer versions of the instrument (assessed in the child's classroom, $\mathrm{r}=.12$ ) were low but statistically significant ( $p$ 's $<.0001$ and .022 , respectively). Alpha coefficients for were .78 for Social Skills .77 and Problem Behavior scales.

\section{Procedure}

The Clinic group mothers completed the QPQ, SSRS and demographic information as part of a larger packet of questionnaires mailed out prior to screening for treatment. The return rate was greater than $75 \%$. Community group mothers were approached at public locations (waiting outside movie theaters, in front of public schools, waiting at parks, shopping malls and playgrounds) by a laboratory assistant wearing a photo identification badge. Potential participants were asked if they had at least one child between the ages of 7 and 12 years. If so, they were asked if they would fill out the QPQ and a brief demographic sheet on one of their children (determined by the laboratory assistant as most closely matching a child in the Clinic group).

Community group mothers agreeing to participate were handed an information sheet describing the purpose of the study and were told not to identify themselves on written materials they were to turn in. The mothers deposited completed questionnaires in a sealed box to preserve anonymity. Due to the nature of participation, the questionnaire burden was kept to a minimum in this group to decrease potential attrition. Positive responses to one question on the demographic sheet, "Do you think your child has trouble either making or keeping friends," was the basis for exclusion from the study. Five subjects were excluded because their mother responded affirmatively to this question. Nine other subjects declined to participate.

\section{Data Analysis Plan}

Items 1-17 were first submitted to preliminary factor analyses for each gender and each group to ensure that the factor structure of the final scale was similar for these divisions. A factor analysis with gender and group combined suggested the final version of the factor based scales. Coefficient alpha was used to test the internal consistency of the resulting scales. Scales with adequate internal consistency were tested for discriminative validity by comparing Clinic and Community groups with ANOVA. The scales were also validated by correlation with SSRS scales.

\section{Results}

We performed separate preliminary factor analyses for each gender with orthogonal (varimax) rotations on differing numbers of factors suggested by the scree plots to identify the most robust solution (SAS User's Guide: Statistics 1985). We used an orthogonal solution, since a scale could be comprised of a summary score from a set of items. This is apt to be more convenient for clinical use.

We found that substantial groupings of items (i.e., at least five items per factor) occurred for each gender when no more than two factors were rotated. Therefore, we selected this solution as the most plausible. The two factor solution accounted for 37.2 , and $37.1 \%$ of the common variance for boys and girls, respectively and 38.8 and $36.8 \%$ of the variance for clinic and community groups, respectively. Items which were not stable across boys and girls (the first 5 items and item 8, "played without each other,") were deleted from subsequent analysis. We performed a principal components factor analysis on the total sample of children. Two factors were again suggested for rotation by departures from chance pattern in the scree plot of unrotated factors. Substantial groupings of items 
occurred when no more than two factors were rotated using the varimax rotation. Item loadings for the total sample were consistent with the preliminary analyses for boys and girls. The two-factor solution accounted for $52.8 \%$ of the common variance.

Table 2 presents items, descriptive labels, and varimax factor loadings of the final scales for the total sample of subjects. A cutoff loading of .51 was employed in order to reduce overlap between factor-based scales. The first factor (7 items) was labeled Conflict, since all of the items involved negative interactions with the guest. The second factor (4 items) was labeled Disengage, since all items involved decreasing the intensity of the play experience with the guest. Parent ratings for each item were summed to form the Conflict and Disengage factor based scales. Coefficient alpha was calculated as .87 for the Conflict factor-based scale but only .53 for the Disengage factor-based scale. Due to the small number of items and consequently low internal consistency of the Disengage factor-based scale, only the Conflict scale was considered further.

Race (dichotomized, due to small $n$ 's, as White versus non-White) and marital status were submitted to ChiSquare analysis. The square-root transformation was used to normalize variances. Neither variable was significantly associated with sample $(p$ 's $>.06)$. Child age, SES, the Conflict factor-based scale and frequency of reported play dates at each location of play (Invited or Hosted play dates) were submitted to $2 \times 2$ (Group X Gender) fixed-effects ANOVAs. Neither child age nor SES reached significance ( $p$ 's $>$.26). The significant results from the analysis of the
Conflict factor-based scale and location of play variables are presented in Table 3.

Inspection of the table reveals that the mean Conflict score was significantly higher in the Clinic (mean $=5.3$ ) than in the Community group [mean $=2.9 ; F(1,156)=$ $6.51, p<.05]$. Both hosted and invited play dates occurred more frequently for the Community group (means $=3.8$ and 3.7, respectively) than for the Clinic group [means = 2.2 and 2.0, respectively; $F(1,156)=9.87$ and 20.34 , $p$ 's $<.005$ and .001$]$. No other main effects or interactions were significant.

A cutting score of 3.5 on the Conflict factor-based scale resulted in correct classification of $66.7 \%$ of the Clinic group and $72.3 \%$ of the Community group. A cutting score of 2.5 for Invited play dates resulted in correct classification of $66.7 \%$ of the Clinic group and $60.7 \%$ of the Community group. A cutting score of 2.5 for Hosted play dates resulted in correct classification of $66.7 \%$ of the Clinic group and $59.8 \%$ of the Community group.

\section{Concurrent Validity with the SSRS}

We submitted the Conflict factor-based scale scores, the assertion and self control subscales of the Social Skills scale and the externalizing, internalizing and hyperactivity subscales of the Problem Behaviors scale to correlation analysis. Results revealed that the correlations between Conflict factor-based scale and the externalizing subscale $(R h o=.44, d f=36, p<.01)$ and between the Conflict factor-based scale and the hyperactivity subscale
Table 2 Original Items and varimax rotated factor pattern for the final analysis of the quality of play questionnaire

Factor loadings have been multiplied by 100 . Items loading above cutoff are in bold

\begin{tabular}{lcc}
\hline Item & Factor & \\
\cline { 2 - 3 } & Conflict & Disengage \\
\hline Chasing, running, hiding, climbing, sports or physically active & - & - \\
Cards or board games & - & - \\
Imaginary or pretend games & - & - \\
Arts/crafts/making things & - & - \\
Talk & - & $\mathbf{5 9}$ \\
Computer or video games & 19 & $\mathbf{6 0}$ \\
Watch TV or videos & -11 & - \\
Played without each other & - & -12 \\
Didn't share a toy, game, etc. & $\mathbf{5 4}$ & 5 \\
Got upset at each other & $\mathbf{8 3}$ & 8 \\
Argued with each other & $\mathbf{8 6}$ & 5 \\
Criticized or teased each other & $\mathbf{7 8}$ & 1 \\
Were bossy with each other & $\mathbf{7 1}$ & $\mathbf{7 0}$ \\
Had brother or sister into play & -4 & $\mathbf{6 8}$ \\
Had other children into play & 10 & 14 \\
Needed a parent to solve problems & $\mathbf{7 0}$ & 6 \\
Annoyed each other & $\mathbf{8 5}$ & \\
\hline
\end{tabular}


Table 3 Mean QPQ scores for clinic and community groups

\begin{tabular}{llllllll}
\hline QPQ score & Mean & & \multicolumn{2}{l}{ Standard deviation } & $p$ \\
\cline { 2 - 3 } & Community & Clinic & & Community & Clinic & \\
\hline Conflict score & 2.9 & 5.3 & & 3.3 & 4.1 & $<.05$ \\
Invited play dates & 3.7 & 1.9 & & 2.7 & 2.0 & $<.001$ \\
Hosted play dates & 3.8 & 2.2 & & 2.6 & 2.1 & $<.005$ \\
\hline
\end{tabular}

$($ Rho $=.38, d f=36, p<.025)$ reached significance. No other correlations were significant ( $p$ 's $>.09$ ).

\section{Discussion}

We present the development of a measure of the quality (i.e., conflict) and frequency of play dates. As hypothesized, community and clinical samples differed significantly on both types of measures. The group difference in mean rates of play dates may either reflect the parent's motivation to arrange these play dates or the parent's availability to supervise. Parents working full-time, whose children attend after care at school, children who attend weekend classes, or children who move between households in divorced families will have fewer hours available for play dates and thus frequency of play dates may decrease. Further research must clarify this issue.

We could establish cutting points for play date frequency and conflict which had adequate sensitivity and specificity with regard to correct identification of community and clinic samples. The correlations between the conflict scale with both externalizing and hyperactivity SSRS subscales validated the Conflict scale as being related to problematic behaviors. Since the QPQ is based only upon parent report, concurrent validity with other assessment methods and raters needs to be investigated. We have begun to do this and have reported Spearman correlations between teen and parent ratings of .55 for the Conflict scale, .97 for Host, and .94 for Guest (all $p$ 's $<.001$; Laugeson et al. 2009). Future research should compare the parent reported QPQ with observational measures of play dates. Such research is in the planning stages.

Clinical interviews suggested that children referred for peer problems have greater conflict on play dates as well as lower frequencies of play dates when compared to nonreferred children. Our study lends support for this clinical finding. The absence of conflict has been identified in the friendship literature as critical to the maintenance of the play date and ultimately the friendship (Ladd 1992). Thus interventions which focus upon improving the quality of play dates are essential to improve peer relationships.
The QPQ has been useful in assessing clinical outcome of children (Frankel et al. 2010b) and teens (Laugeson et al. 2009) with ASD. In both studies, the intervention resulted in significantly less conflict and more hosted play dates than the wait list control group, as measured by the QPQ. Frankel et al. (2010b) reported that the number hosted play dates by children with ASD was significantly and positively correlated with mutual and direct social behavior with peers such as offering objects, conversing, toy-taking, other activities with a turn-taking structure) and positive peer response to the initiations of the child with ASD.

Ladd and Golter (1988) reported that $94 \%$ of the peer contacts they assessed involved accompanied parental monitoring, and only 6\% were unsupervised. Although parents were instructed to complete the QPQ based upon a play date they observed, it is possible that the level of supervision of play dates differed between non clinicreferred and clinic referred samples. Future research must more closely assess the level of parental supervision.

There are four additional limitations which should be addressed in future research. (a) The recruitment procedures for the community group (approaching them in public places) may have biased the community sample toward more sociable, active families. Future research should employ more similar recruitment procedures for clinic and community groups. (b) Test retest reliability will also need to be assessed. (c) Positive qualities of play dates were not measured by the QPQ and neither is the child's experience on the play date. These should be considered in the development of future instruments. (d) Play dates seem ubiquitous in our society among elementary school-aged children and young teens. It is left for future research to establish how common are play dates among various cultures and races and in varying SES.

Open Access This article is distributed under the terms of the Creative Commons Attribution Noncommercial License which permits any noncommercial use, distribution, and reproduction in any medium, provided the original author(s) and source are credited.

\section{Appendix: UCLA Children's Friendship Program}

Quality of Play Questionnaire: Parent

\section{Instructions to Parent}

We would like information on your child's playmates. We only want to know about your child's playmates that you have invited over to your house in order to play alone with your child.

Do not consider children who only did homework together, or were over only as part of a group, party, or outing or only went to a movie together. 
Please fill in the first name of the playmate that has played alone with your child at your house most often in the past month. If your child hasn't played with anyone like this for the past month, put the name of the child who last played with your child at your house and you were around to see or hear what was happening.

Playmate's name

Please indicate below what you saw the last time they played together.

Circle one number in each row:

\begin{tabular}{lllll}
\hline How the children spent their time & $\begin{array}{l}\text { Not at } \\
\text { all }\end{array}$ & $\begin{array}{l}\text { Just a } \\
\text { little }\end{array}$ & $\begin{array}{l}\text { Pretty } \\
\text { much }\end{array}$ & $\begin{array}{l}\text { Very } \\
\text { much }\end{array}$ \\
\hline $\begin{array}{l}\text { 1. Chasing, running, hiding, } \\
\text { climbing, sports or physically }\end{array}$ & 0 & 1 & 2 & 3 \\
active & & & & \\
2. Cards or board games & 0 & 1 & 2 & 3 \\
3. Imaginary or pretend games & 0 & 1 & 2 & 3 \\
4. Arts/crafts/making things & 0 & 1 & 2 & 3 \\
5. Talk & 0 & 1 & 2 & 3 \\
6. Computer or video games & 0 & 1 & 2 & 3 \\
7. Watch TV or videos & 0 & 1 & 2 & 3 \\
\hline
\end{tabular}

What the children did during this visit:

\begin{tabular}{lllll}
\hline They... & $\begin{array}{l}\text { Not at } \\
\text { all }\end{array}$ & $\begin{array}{l}\text { Just a } \\
\text { little }\end{array}$ & $\begin{array}{l}\text { Pretty } \\
\text { much }\end{array}$ & $\begin{array}{l}\text { Very } \\
\text { much }\end{array}$ \\
\hline 8. played without each other & 0 & 1 & 2 & 3 \\
9. didn't share a toy, game, etc. & 0 & 1 & 2 & 3 \\
10. got upset at each other & 0 & 1 & 2 & 3 \\
11. argued with each other & 0 & 1 & 2 & 3 \\
12. criticized or teased each other & 0 & 1 & 2 & 3 \\
13. were bossy with each other & 0 & 1 & 2 & 3 \\
14. had brother or sister into play & 0 & 1 & 2 & 3 \\
15. had other children into play & 0 & 1 & 2 & 3 \\
16. needed a parent to solve problems & 0 & 1 & 2 & 3 \\
17. annoyed each other & 0 & 1 & 2 & 3 \\
\hline
\end{tabular}

18. Play at another child's house: Please try to recall the times your child was invited to another child's house as the only invited guest.

Number of visits like this (to any child's house) in the last month

19. Play at your house: Please try to recall the times you invited another child to your house as the only invited guest.

Number of visits like this (by any child) in the last month

\section{References}

Atkins, M., \& Pelham, W. E. (1991). School-based assessment of attention deficit-hyperactivity disorder. Journal of Learning Disabilities, 24, 197-204.

Cousins, L. S., \& Weiss, G. (1993). Parent training and social skills training for children with attention-deficit hyperactivity disorder: How can they be combined for greater effectiveness? Canadian Journal of Psychiatry, 38, 449-457.

Frankel, F. (2010). Friends forever: How parents can help their kids make and keep good friends. San Francisco: Jossey-Bass.

Frankel, F., Gorospe, C. M., Chang, Y., \& Sugar, C. A. (2010a). Mothers' reports of play dates and observation of school playground behavior of children having high-functioning autism spectrum disorders. Journal of Child Psychology \& Psychiatry (in press).

Frankel, F., \& Myatt, R. (2003). Children's friendship training. New York: Brunner-Routledge.

Frankel, F., Myatt, R., Cantwell, D. P., \& Feinberg, D. T. (1997). Parent assisted children's social skills training: Effects on children with and without attention-deficit hyperactivity disorder. Journal of the Academy of Child \& Adolescent Psychiatry, 36, 1056-1064.

Frankel, F., Myatt, R., \& Feinberg, D. T. (2007). Parent friendship training for children with Autism Spectrum Disorders: Effects of psychotropic medication. Child Psychiatry and Human Development, 37, 337-346.

Frankel, F., Myatt, R., Whitham, C., Gorospe, C. M., Sugar, C., \& Laugeson, E. A. (2010b). A randomized controlled study of parent-assisted children's friendship training with children having autism spectrum disorders. Journal of Autism and Developmental Disabilities, 40, 827-842.

Gest, S. D., Graham-Bermann, S. A., \& Hartup, W. W. (2001). Peer experience: Common and unique features of number of friendships, social network centrality, and sociometric status. Social Development, 10, 23-40.

Gifford-Smith, M. E., \& Brownell, C. A. (2003). Childhood peer relationships: Social acceptance, friendships, and peer networks. Journal of School Psychology, 41, 235-284.

Gottman, J. M. (1983). How children become friends. Monographs of the Society for Research in Child Development, 48(3), 1-85.

Gresham, F. M., \& Elliott, S. N. (1990). Social skills rating system: Manual. Circle Pines, MN: American Guidance Service.

Hartup, W. W. (1996). The company they keep: Friendships and their developmental significance. Child Development, 67, 1-13.

Koegel, R. L., Werner, G. A., Vismara, L. A., \& Koegel, L. K. (2005). The effectiveness of contextually supported play date Interactions between children with Autism and typically developing peers. Research and Practice for Persons with Severe Disabilities, 30(2), 93-102.

Ladd, G. W. (1992). Themes and theories: Perspectives on processes in family-peer relationships. In R. D. Parke \& G. W. Ladd (Eds.), Family-peer relationships: Modes of linkages (pp. 3-34). Hillsdale, NJ: Lawrence Earlbaum.

Ladd, G. W., \& Golter, B. S. (1988). Parents' management of preschooler's peer relations: Is it related to children's social competence? Developmental Psychology, 24, 109-117.

Ladd, G. W., \& Hart, C. H. (1992). Creating informal play opportunities: Are parents' and preschoolers' initiations related to children's competence with peers? Developmental Psychology, 28, 1179-1187.

Ladd, G. W., Hart, C. H., Wadsworth, E. M., \& Golter, B. S. (1988). Preschooler's peer networks in nonschool settings: Relationship to family characteristics and school adjustment. In S. Salzinger, J. Antrobus, \& M. Hammer (Eds.), Social networks of children, 
adolescents, and college students (pp. 61-92). Hillsdale, NJ: Lawrence Erlbaum.

Ladd, G. W., Kochenderfer, B. J., \& Coleman, C. C. (1996). Friendship quality as a predictor of young children's early school adjustment. Child Development, 67, 1103-1118.

Laugeson, E. A., Frankel, F., Mogil, C., \& Dillon, A. R. (2009). Parent-assisted social skills training to improve friendships in teens with Autism Spectrum Disorders. Journal of Autism and Developmental Disorders, 39, 596-606.

Nangle, D. W., Erdley, C. A., Newman, J. E., Mason, C. A., \& Carpenter, E. M. (2003). Popularity, friendship quantity, and friendship quality: Interactive influences on children's loneliness and depression. Journal of Clinical Child \& Adolescent Psychology, 32, 546-555.

Newson, J., \& Newson, E. (1976). Seven years old in the home environment. New York: Wiley.

Parke, R. D., \& Bhavnagri, N. P. (1989). Parents as managers of children's peer friendships. In D. Belle (Ed.), Children's social networks and social supports (pp. 241-259). New York: Wiley.

Parker, J. G., \& Asher, S. R. (1993). Friendship and friendship quality in middle childhood: Links with peer group acceptance and feelings of loneliness and social dissatisfaction. Developmental Psychology, 29, 611-621.

Pfiffner, L. J., \& McBurnett, K. (1997). Social skills training with parent generalization: Treatment effects for children with Attention Deficit Disorder. Journal of Consulting Clinical Psychology, 65, 749-757.

Reich, W. (2000). Diagnostic Interview for children and adolescents (DICA). Journal of the American Academy of Child \& Adolescent Psychiatry, 39, 59-66.

SAS. (1985). SAS user's guide: Statistics. Cary, NC: SAS Institute.

Steinberg, L. (1986). Latchkey children and susceptibility to peer pressure: An ecological analysis. Developmental Psychology, 22, $433-439$. 